\title{
Coronary Angiographic Patency in Patients With Acute Myocardial Infarction With or Without Thrombolytic Therapy
}

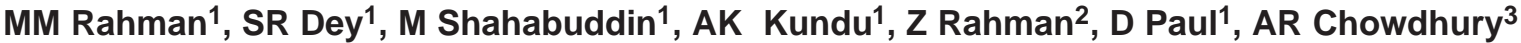 \\ ${ }^{1}$ Department of Cardiology,SOMCH. ${ }^{2}$ Department of Cardiology, NICVD. \\ ${ }^{3}$ Department of Cardiology,BSMMU.
}

\begin{abstract}
Keywords:
Myocardial

infarction,

Thrombolytic

therapy,

Streptokinase,

Coronary

angiographic

patency.
\end{abstract}

\begin{abstract}
Background: The myocardial infarction (MI) is a leading cause of morbidity and mortality in developed countries as well as in developing countries including Bangladesh. Streptokinase since its introduction has been shown to reduce mortality significantly. The outcome of $M I$ treated with streptokinase can be evaluated either by CAG measurement of TIMI blood flow or by the measurement of ST segment resolution in 12 lead ECG.

Methods: This cross sectional comparative study was conducted in the department of Cardiology in Sylhet M A G Osmani Medical college, to compare the patency between MI patients with or without streptokinase therapy, from Jan 2008 to Dec 2009. Considering enrollment criteria a total of 96 patients with acute MI were evaluated. All patients were categorized into two groups. Group-I $(n=48)$, who received streptokinase and Group-II $(n=48)$, who did not received the same(due to late presentation). CAG was done with in 7-28 days of on set of pain. The patients admitting in coronary care unit with the diagnosis of STEMI were taken as the study subjects.

Results: Adequate TIMI (thrombolysis in myocardial infarction) flow was higher who received streptokinase (85.4\%) than those who did not receive the therapy (52.1\%).

Conclusion: This study indicates that streptokinase therapy is associated with rapid and sustained reperfusion of the infarct related artery in the treatment of acute myocardial infarction.
\end{abstract}

(Cardiovasc.j. 2011; 3(2): 136-142)

\section{Introduction:}

Cardiovascular disease is the largest killer in developed countries and is rapidly assuming a similar role in developing ones. It has been predicted that cardiovascular disease will be the most important cause of mortality by the year 2015 . Bangladesh is a small country with vast population (>120 million). Health statistics in this country have multiple limitations. There are only a few studies conducted among general population to see the prevalence of Ischaemic Heart Disease (IHD). Limited number of data are available which are mostly based on small size population based crosssectional survey. The average prevalence of IHD from 3 small scale population based studies in Bangladesh was 6.56/thousand. ${ }^{1}$

Bangladeshi people, as other south Asians, have high susceptibility to ischemic heart disease (IHD) but population- based data are lacking in Bangladesh. A prevalence of 3.4\% was recorded in rural and agricultural free living population with traditional lifestyle and thin body mass index. ${ }^{2}$
Streptokinase since its introduction has been shown to reduce mortality significantly and the reduction is inversely proportional to the time that treatment is initiated from symptom onset for patients treated in first 60 minutes of symptom onset, the so called "golden hour" mortality is reduced by more than $50 \%$. Even frank prevention of the event can be assured in many patients treated in this early time frame. Fletcher and colleagues reported the first use of thrombolytic therapy in patients with acute myocardial infarction in 1958. In the early 1960s and1970s, 24 trials were performed evaluating the efficacy of intravenous streptokinase. ${ }^{3}$

Thrombolytic therapy is given because of its ability to breakdown clots in the infarct related artery, restore blood flow, salvage myocardium, preserve left ventricular function and reduce mortality. It was first used in the late 1950s in patients with myocardial infarction. It was not until the mid 1980s when angiographic observation of reperfusion among patients receiving intracoronary streptokinase prompted the move towards

Address of Correspondence: Dr. MM Rahman, Department of Cardiology, Sylhet MAG Osmani Medical College \& Hospital, Sylhet, Bangladesh 
thrombolytic therapy as a wide-ranging treatment option. ${ }^{4}$

Most infarctions are precipitated by thrombi, and early fibrinolytic treatment should therefore be the rational therapy. Recanalization is achieved in three of four patients where streptokinase is applied intracoronary or intravenously. Very early treatment, started within one hour from the onset of nitroglycerin-resistant chest pain, may prevent infarction in some patients. Streptokinase reduces mortality after infarction, in total by as much as 25 percent, and even considerably more when infusion is started early. ${ }^{5}$

Successful thrombolytic treatment for myocardial infarction is associated with rapid, complete, and sustained perfusion of the infarct related artery. The degree of perfusion achieved in the infarct related artery has traditionally been expressed as the thrombolysis in myocardial infarction (TIMI) trial flow grade, which correlates with survival after myocardial infarction. The outcome of acute myocardial infarction treated with thrombolytic therapy can be evaluated either by coronary angiographic measurement of TIMI (Thrombolysis In Myocardial Infarction) blood flow or by the measurement of ST segment resolution at $90 \mathrm{~min}$ after streptokinase infusion, in 12 lead electrocardiogram. ${ }^{6}$

Several noninvasive markers for identifying infarction related artery (IRA) patency have been tried, including the resolution of chest pain, presence of reperfusion arrhythmia and the release pattern of serum markers of cardiac injury, but coronary angiography (CAG) is considered as the "Gold standard".

The therapeutic goals in acute myocardial infarction are to retard coagulation and platelet function, open the affected coronary artery and achieve the greatest degree of myocardial reperfusion in the shortest possible time. As access to primary angioplasty is often limited, thrombolytic drugs are the most powerful agents currently available for reversing coronary arterial occlusion in the majority of patients. ${ }^{8}$

The current recommendation is to treat patients with STEMI who seek medical attention within 12 hours of the onset of symptoms with reperfusion therapy, either primary PCI or thrombolytic therapy. Patients without ST segment elevation (previously labeled 'non-Q wave' infarction) do not benefit, and may derive harm, from thrombolysis. ${ }^{9}$

Acute myocardial infarction is a major public health problem all over the world including Bangladesh. Though there are various studies available in our country on angiographic patency, no study was done using coronary angiogram (CAG) in this region of Bangladesh. This study was done to compare the coronary artery patency between acute MI patients with or without streptokinase therapy.

\section{Materials and Methods:}

The study was a cross sectional comparative study. The study was carried out over a period of two years from $1^{\text {st }}$ Jan. 2008 to $31^{\text {st }}$ December 2009 in the Department of Cardiology, Sylhet M A G Osmani Medical College Hospital. All patients admitted in coronary care unit with the diagnosis of ST elevation myocardial infarction fulfilling enrollment criteria were taken as the study subjects. A total of 96 subjects - acute MI patients who received streptokinase within 12 hours of onset of chest pain were treated as Group- $\mathrm{I}=48$, while acute MI patients who did not receive thrombolytic therapy because of delayed presentation (12 hours after onset of chest pain) were considered as Group-II $=48$, were included in the study.

Inclusion criteria ST- segment elevation myocardial infarction, characterized by symptoms of myocardial ischemia and ST- segment elevation greater than $0.1 \mathrm{mV}$ in two contiguous leads or new (or presumably new) left bundle-branch block on the presenting ECG were included in the study. 10

\section{Exclusion criteria}

(1) Previous MI

(2) Cardiomyopathy

(3) Systemic diseases affecting the heart

(4) Myocarditis

(5) Valvular heart disease

(6) Congenital heart disease

(7) If streptokinase was contraindicated

(8) In whom coronary angiogram could not be done. 
The Group-I received streptokinase (streptase) at a dose of 1.5 million units, diluted in $100 \mathrm{ml}$ of normal saline, intravenously, in 1 hour. Complications like hypotension, shock, hemorrhagic manifestation etc. following streptokinase were noted. Informed consent were taken from all the patients. Coronary angiogram was done within 7-28 days of onset of pain of all patients. The coronary angiograms were performed by the cardiologists of the department. The films were reviewed and the coronary patency were classified according to the TIMI flow. Matching was done based on - Visual assessment of TIMI (thrombolysis in myocardial infarction) flow. Morphology of the lesion. Types of the lesion. Ethical clearance was obtained and data was processed and analyzed using soft-ware SPSS for windows, version 11.5.

\section{TIMI - flow evaluation. ${ }^{11}$}

1. TIMI flow grade -3 (complete reperfusion) :

2. TIMI flow grade -2: (partial reperfusion):

3. TIMI flow grade-1: (penetration with minimal perfusion)

4. TIMI flow grade- 0 : (no perfusion):

Distribution of ECG changes in infarction. ${ }^{12}$

1. Anteroseptal infarction produces changes in one or more of the leads V1 to V4.

2. Anterolateral infarctionproduces changes from V4 to V6, and lead I and aVL.

3. Anterior infarction is indicated by more widespread changes including most of the leads from V1 to V6, as well as lead I and aVL.

4. Inferior(or diaphramatic) infarction is registered by changes in lead II, III and aVF.

5. Strictly posterior myocardial infarction does not produce $Q$ waves in the standard 12 leads. However the loss in electrical activity from the posterior part of the left ventricle, leads to a tall $\mathrm{R}$ in $\mathrm{V} 1$, because the forces depolarising the left ventricle are unopposed.

6. Right ventricular infarction (which is almost always associated with inferior infarction) produces transient ST elevation in V4R.

7. Further leads may be required for infarcts in unusual sites, V7 and V8 being helpful in lateral infarcts, and leads in the second or third intercostal spaces for high anterior and lateral infarcts.

\section{Results:}

Table-I

Distribution of patients by age $(n=96)$

\begin{tabular}{lcc}
\hline Age (years) & Frequency & Percentage \\
\hline$\leq 40$ & 22 & 22.9 \\
$41-50$ & 44 & 45.8 \\
$>50$ & 30 & 31.3 \\
\hline
\end{tabular}

\# Mean age $=47.8 \pm 10.5$ years; range $=24-70$ years

Sex: Figure 1 shows the sex distribution of the patients. Out of 96 patients, majority 95(99\%) were male and only 1 was female.

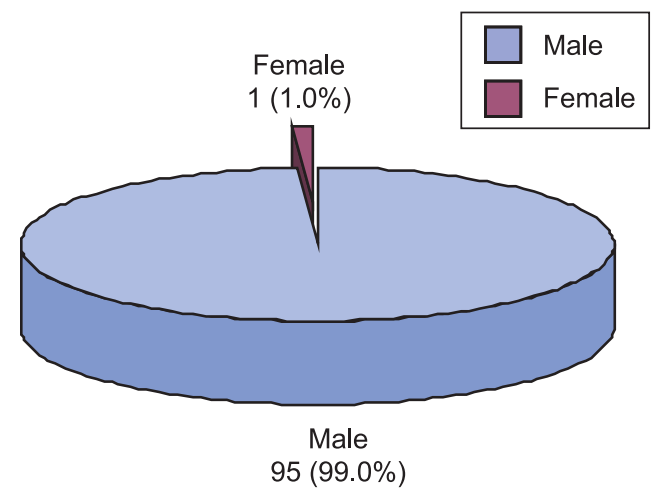

Fig.-1: Distribution of patients by sex $(n=96)$

Occupation:

Table II

Distribution of patients by occupation $(n=96)$

\begin{tabular}{lcc}
\hline Occupation & Frequency & Percentage \\
\hline Farmer & 05 & 5.2 \\
Business & 03 & 3.1 \\
Sedentary jobs & 37 & 38.5 \\
Non-sedentary job & 37 & 38.5 \\
Others & 12 & 12.5 \\
\hline
\end{tabular}

Risk factors:

Table-III

Distribution of patients by risk factors $(n=96)$

\begin{tabular}{lcc}
\hline Risk factors & Frequency & Percentage \\
\hline Hypertension & 08 & 8.3 \\
Diabetes & 22 & 22.9 \\
Smoking & 73 & 76.0 \\
Dyslipidaemia & 04 & 4.2 \\
Family history of IHD & 45 & 46.9 \\
Physical inactivity & 78 & 81.3 \\
\hline
\end{tabular}


Total will not correspond to $100 \%$ for some patients had multiple risk factors.

Comparison of TIMI flow in infarct related arteries between two groups:

Table IV shows the association between reperfusion with streptokinase therapy and angiographic patency (in terms of TIMI flow). Adequate TIMI flow was appreciably higher among patients who received reperfusion therapy with streptokinase (85.4\%) than those who did not receive the therapy (52.1\%). The likelihood of adequate TIMI flow in patients who are reperfused with streptokinase is more than 5-fold ( OR=5.39; 95\% of CI $=2.020$ 14.378) higher than those who are not reperfused with the same thrombolytic agent $(p<0.001)$.

Figures in the parentheses denote corresponding percentage. Adequate TIMI flow i.e TIMI 2 or 3. Inadequate TIMI flow i.e TIMI 0 or $1 .{ }^{13}$
Comparison of TIMI flow in infarct related arteries in anterior $M I(L A D)$ between two groups:

Table V shows the TIMI flow in infarct-related arteries in anterior MI (LAD). The subjects with anterior MI of group-I had significantly higher incidence of adequate TIMI flow in LAD compared to group-II $(p<0.001)$.

Comparison of TIMI flow in infarct related arteries in Inferior MI:

Table VI and X show the TIMI flow in infarct-related arteries in Inferior MI. The subjects with Inferior MI of group-I had significantly higher incidence of adequate TIMI flow in RCA and LCX compared to group-II ( $\mathrm{p}=0.038$ and $\mathrm{p}=0.033$ respectively).

The complications of thrombolytic therapy:

The patients in the streptokinase group developed more complication than non receiving streptokinase group and the difference was statistically significant $(\mathrm{p}=0.001)$.

Table-IV

Comparison of TIMI flow in infarct related arteries between two groups

\begin{tabular}{|c|c|c|c|c|}
\hline \multirow[t]{2}{*}{ Streptokinase Therapy } & \multicolumn{2}{|c|}{ TIMI flow } & \multirow[t]{2}{*}{ Odds Ratio(95\% of CI) } & \multirow[t]{2}{*}{$\mathrm{p}$-value } \\
\hline & Adequate & Not Adequate & & \\
\hline Received $(n=48)$ & $41(85.4)$ & $7(14.6)$ & $5.39(2.020-14.378)$ & $<0.001$ \\
\hline Not received $(n=48)$ & $25(52.1)$ & $23(47.9)$ & & \\
\hline
\end{tabular}

Table-V

TIMI flow in infarct-related arteries in anterior MI(LAD) between groups

\begin{tabular}{llll}
\hline TIMI flow in LAD & \multicolumn{2}{c}{ Study Group } & p-value \\
\cline { 2 - 3 } & Group-I $(\mathrm{n}=28)$ & Group-II $(\mathrm{n}=32)$ & \\
\hline AdequateInadequate & $26(92.9) 2(7.1)$ & $17(53.1) 15(46.9)$ & 0.001 \\
\hline
\end{tabular}

Figures in the parenthesis denote corresponding percentage.

Table-VI

TIMI flow in infarct-related arteries in inferior MI (RCA)

\begin{tabular}{lccc}
\hline TIMI flow in RCA & \multicolumn{2}{c}{ Study Group } & p-value \\
\cline { 2 - 4 } & Group-I $(\mathrm{n}=14)$ & Group-II (n=12) & \\
\hline AdequateInadequate & $12(85.7) 2(14.3)$ & $5(41.7) 7(58.3)$ & 0.038 \\
\hline
\end{tabular}

Figures in the parenthesis denote corresponding percentage.

Table-VII

TIMI flow in infarct-related arteries in inferior MI (LCX)

\begin{tabular}{lccc}
\hline TIMI flow in LCX & \multicolumn{2}{c}{ Study Group } & p-value \\
\cline { 2 - 4 } & Group-I $(\mathrm{n}=6)$ & Group-II $(\mathrm{n}=4)$ & \\
\hline AdequateInadequate & $5(83.33) 1(16.66)$ & $1(25.0) 3(75.0)$ & 0.033 \\
\hline
\end{tabular}

Figures in the parenthesis denote corresponding percentage. 
Table-VIII

The complications of thrombolytic therapy

\begin{tabular}{lccc}
\hline Complications & \multicolumn{2}{c}{ Study group } & *p value \\
\cline { 2 - 3 } & Group -1(n=48) & Group-2 $(\mathrm{n}=48)$ & \\
\hline Hypotension & $11(22.9 \%)$ & $2(4.2)$ & 0.001 \\
Bleeding manifestations & $3(6.2 \%)$ & $0(0.0)$ & \\
Allergic reaction & $2(4.2 \%)$ & $0(0.0)$ & \\
Others & $0(0.0 \%)$ & $0(0.0)$ & \\
\hline
\end{tabular}

Total will not correspond to $100 \%$ for some patients had multiple responses. Figures in the parenthesis denote corresponding percentage.

\section{Discussion:}

The aim of the study was to compare the coronary patency between acute MI patients with or without streptokinase therapy.

In this study, mean age of patient was $47.8 \pm 10.5$ years (Table I). Highest number of patients (about $45.8 \%$ ) was in the age group 41-50 years. The mean age corresponds with mean age of population studied by Chowdhury et al., ${ }^{14}$ where it was $48.5+9.1$ years. In the current study $22.9 \%$ of patients were below 40 years of age group. This observation correlates with the report of Khandaker et al. ${ }^{15}$ where the study found $18.74 \%$ of the patients were under 40 years of age. This figure $(22.9 \%)$ highlights the fact that acute myocardial infarction is increasing in the younger age group of our country.

Out of 96 patients, there were 95(99\%) male and $1(1 \%)$ female patients (figure 5). The number of female patients were low in almost all relevant studies. Khandaker et al. ${ }^{15}$ reported $11.37 \%$ of female patient, and Chowdhury et al. ${ }^{14}$ recorded $8.7 \%$ in their study. In the current study few number of female was due to their refusal to undergo CAG by a male cardiologist.

In terms of occupation business and sedentary jobs were prime occupations (each $38.5 \%$ ). Non sedentary jobs were the second leading occupation $(12.5 \%)$, followed by service $(5.2 \%)$ and other occupations (2.1\%).

Though smoking is a common risk factor, in the current study physical inactivity was found as the commonest risk factor (80\%) followed by smoking $(76 \%)$, positive family history of ischaemic heart disease $(46.9 \%)$, diabetes mellitus (23\%), hypertension (8.3\%), and dyslipidaemia (4.2\%). Malik et al. ${ }^{16}$ found smoking as the greatest risk factor $(81.8 \%)$ followed by hypertension (58.9\%) and diabetes mellitus (47.1\%) and family history of IHD (40.4\%). Physical inactivity is increasing as a risk factor in our country.

When adequate TIMI flow of infarct related coronary artery between Group -I and Group-II were compared (Table-VII) a significant difference was observed. The association between reperfusion with streptokinase therapy and angiographic patency (in terms of TIMI flow) shows that adequate TIMI flow was appreciably higher among patients who received reperfusion therapy with streptokinase $(85.4 \%)$ than those who did not receive the therapy (52.1\%) i.e. for those receiving SK therapy patency > non-patency. The likelihood of adequate TIMI flow in patients who were reperfused with streptokinase is 5 -fold $(\mathrm{OR}=5.39$; $95 \%$ of $\mathrm{CI}=2.020-14.378$ ) higher than those who were not reperfused with the same thrombolytic agent $(p<0.001)$. Steg et al. ${ }^{17}$ found timi flow 2 or 3 in $77.4 \%$ with SK therapy (after $90 \mathrm{~min}$ ). A patent vessel was found to be $76 \%$ when angiography was done $2.9+2.8$ days after administration of SK. ${ }^{18}$

Uriel et al. ${ }^{19}$ found that spontaneous reperfusion of the infarct related artery occurs in $7-27 \%$ of patients experiencing acute STEMI. Topol ${ }^{20}$ found that the pooled 90 minute patency for SK is $51 \%$ as compared to no therapy until 90 minutes where the rate is $24 \%$ importantly after the 90 minutes point there appears to be steep rate of further increases patency such that at 2 to 3 hours it is $70 \%$ and by 24 hours it $86 \%$. Thus SK is highly effective in achieving infarct vessel patency particularly when assessed at 3 to 24 hours after treatment initiated. Pooled data from a metaanalysis by Ohman et al. (2001) suggests patency rates with streptokinase of approximately $44 \%$ at $60 \mathrm{~min}$ and $48 \%$ at $90 \mathrm{~min}$. Approximately 2 to $3 \mathrm{~h}$ 
after beginning therapy, patency rates were $72 \%$, achieving a rate of between $75 \%$ and $85 \%$ at $24 \mathrm{~h}$ to 21 days after therapy. ${ }^{21}$ At three to four weeks, French et al. ${ }^{22}$ found the patency rate at $73 \%$ for patients receiving streptokinase.

Early spontaneous recanalisation is probably due to relief of coronary spasm, endogeneous lysis of a platelet thrombus or both. ${ }^{23}$ In the current study, since CAG was performed with in 7-28 days of the onset of pain, the percentage of reperfusion found was higher.

Complications of streptokinase therapy were recorded as the following: hypotension (22.9\%), bleeding manifestations (6.2\%), allergic reaction (4.2\%). Similar complications were revealed in a study conducted by Chowdhury et al. ${ }^{14}$ as hypotension (27.0\%), hemorrhagic manifestations $(4.6 \%)$. There was no significant difference between the two studies.

The current study reveals the effectiveness of streptokinase therapy in recanalization of infarct related arteries and salvage of TIMI flow in STelevated myocardial infarction.

\section{Limitations of the study}

1. Number of study population was limited.

2. Angiography could not be done with in 90 minutes of initiation of streptokinase therapy.

3. CAG could not be done on fixed date.

4. All major risk factors could not be evaluated.

5. Fasting lipid profile could not be done.

6. Troponin I could not be done in all patients.

\section{Conclusion:}

This study shows that successful thrombolytic treatment for myocardial infarction is associated with rapid, and sustained perfusion of the infarct related artery. A significantly higher rate of recanalization was achieved in patients where streptokinase was applied intravenously. The study further shows physical inactivity to be the major risk factor in myocardial infarction.

The present study provides evidence of association between reperfusion with streptokinase therapy and angiographic patency of infarct related artery (in terms of TIMI flow). Adequate TIMI flow was appreciably higher among patients who received reperfusion therapy with streptokinase $(85.4 \%)$ than those who did not receive the therapy (52.1\%).

Conflict of Interest - None.

\section{References:}

1. Islam MN, Ali MA, Ali M. Sprectrum of cardiovascular disease: the current scenario in Bangladesh. Bangladesh Heart Journal 2004;19: 1-7.

2. Zaman MM, Ahmed J, Choudhury SR, Numan SM, Parvin K \& Islam MS. Prevalence of ischemic heart disease in a rural population of Bangladesh. Indian Heart $J$ 2007; 59(3):239-41.

3. White H D, Frans J, Werf VD. Thrombolysis for Acute Myocardial Infarction. Circulation 1998; 97: 1632-1646.

4. Tough J. Thrombolytic therapy in acute myocardial infarction. Learning Zone 2005; 55-68.

5. Dale j \& Wik B. Streptokinase treatment in acute myocardial infarction. Tidsskr Nor Laegeforen 1989; 109(4): 429-32.

6. Zairis MN, Lyrus AG, Makrygiannis SS, Psarogianni PK, Adamopoulou EN, Handanis SM. Type 2 diabetes and intravenous thrombolysis outcome in the setting of ST elevation myocardial infarction. Diabetes Care 2004; 27: 967-71.

7. Klootwijk P, Cobbaert C, Floretti KPP, Simoons ML.Noninvasive assessment of reperfusion and reocclution after thrombolysis in acute myocardial infarction. Am J Cardiol 1993; 72: 75-84.

8. Norris RM . Noninvasive diagnosis of arterial patency after thrombolytic treatment and its relation to prognosis. $\mathrm{Br}$ heart $\mathrm{J}$ 1993; 69: 485- 491.

9. Bashore TM, Granger CB, Hranitzky P, Patel MR. Heart Disease. In: McPhee, SJ \& Papadakis, MA. Eds. Current Medical Diagnosis \& Treatment, $48^{\text {th }}$ ed., USA: McGraw-Hill com, 2009: 322.

10. Dellegrottaglie S, Gershlick AG, Massimo C, Gersh BJ. Pharmacologic Therapy for Acute Coronary Syndromes. In: Fuster V, O'Rourke RA, Walse RA, Wilson PP. Eds. Hurst's The Heart, $12^{\text {th }}$ ed., New York: Mc Graw- Hill Companies, Inc.,2008:2: 1415.

11. Khoukaz S, Hermann SC, Kern MJ. Angiography for percutaneous coronary interventions, in Kern, MJ (ed.), The Interventional Cardiac Catheterization Handbook, $2^{\text {nd }}$ ed., Philadelphia: Elsevier, 2009: 130-136.

12. Julian DG, Cowan JC, McLenachan JM.Diseases of the coronary arteries-causes, pathology and prevention. Cardiology, $8^{\text {th }}$ ed., London: Elsevier limited, 2006: $79-122$.

13. Cooper HA, James A, de Lemos JA, David A, Morrow DA.. Minimal ST-segment deviation: A simple, noninvasive method for identifying patients with a patent infarction related artery after fibrinolytic administration. Am Heart J 2002;144(5): 790-795. 
14. Chowdhury MAR, Hossain AKMM, Dey SR, Akhtaruzzaman AKM, Islam NAF. A comparative study on the effect of streptokinase between diabetic and non- diabetic myocardial infarction patients. Bangladesh J Pharmacol 2008; 3: 1-7.

15. Khandaker RK, Hossain D, Hossain M, Zaman S . Reproductive analysis of acute myocardial infarction, A 4 years study on 2690 patients. Bangladesh Heart Journal 1986; 1: 14-17.

16. Malik A, Islam M N, Zafar A, Khan K A, Ramizuddin M. Clinical patterns of ischaemic heart diseases and its association with some known risk factors. Bangladesh Heart journal 1987; 2 : 1-9.

17. Steg PG, Laperche T, Golmard J L, Himbart D, Aubry P. Efficacy of Streptokinase, but Not Tissue-Type Plasminogen Activator, in Achieving 90 minutes Patency after Thrombolysis for Acute Myocardial Infarction Decreases With Time to Treatment. J Am Coll Cardio 1998; 31: 776-779.

18. Bennett JM, Niekerk FJV, Gourassas J, Konstantinides S, Badenhorst, JCW. Intravenous streptokinase in acute myocardial infarction. SAMJ 1988 ; 73:513-515.
19. Uriel N, Moravsky G, Blatt A, Kaluski E, Gabara Z, Yofik I, Hendler A, Krakover. Acute myocardial Infarction with Spontaneous Reperfusion: Clinical Characteristics and Optimal timing for Revascularization. IMAJ 2007; 9: 243-246.

20. Topol EJ. Thrombolytic intervention. In: Topol, EJ. Ed. Text Book of Interventional Cardiology, Philadelphia : W.B. Saunders Company, 1994: 91-118.

21. Ohman EM, Harrintong RA, Cannon CP, Agnelli G, Cairns JA, Kennedy JW. Intravenous Thrombolysis in Acute Myocardial Infarction. Chest 2001; 119 (1): 253S$277 \mathrm{~S}$.

22. French JK, Straznicky IT, webber BJ, Aylward PE, Williams BF, White HD. Angiographic frame counts 90 minutes after streptokinase predict left ventricular function at 48 hours following myocardial infarction. Heart 1999; 81:128-133.

23. Rentrop KP, Feit F, Sherman W, Thornton JC 1989, 'Serial angiographic assessment of coronary artery obstruction and collateral flow in acute myocardial infarction. Report from the second Mount Sinai: New York University Reperfusion Trial. Circulation 1989; 80:1166-1175. 